\title{
Remote controlled practical education for Power Electronics
}

\author{
P.Bauer \\ DELFT UNIVERSITY OF TECHNOLOGY \\ Mekelweg 4 \\ 2628 CD Delft, Netherlands \\ Tel.: $+31 /(0)-15.2784654$ \\ Fax: $+31 /(0)-152782968$ \\ E-Mail: P.Bauer@TUDelft.nl \\ URL: http://www.TUDelft.nl \\ V. Staudt \\ UNIVERSITY OF BOCHUM \\ Lehrstuhl EELE \\ D-44780 Bochum, Germany \\ E-Mail: staudt@eele.rub.de \\ URL:http://www.ruhr-uni-bochum.de/eele/
}

\section{Acknowledgements}

The work has been performed within the project „E-learning Distance Interactive Practical Education (EDIPE)". The project was supported by the European Community within framework of Leonardo da Vinci II program (project No CZ/06/B/F/PP-168022). The opinions expressed by the authors do not necessarily reflect the position of the European Community, nor does it involve any responsibility on its part.

\section{Keywords}

Education methodology, Education tool, Converter circuit, STATCOM, Power Quality

\begin{abstract}
This paper investigates distance learning with particular attention to experimental work.

PEMCWebLab provides the user with a practical experience in Power Electronic education. It was designed based on leading ideas and had clear targets. Virtual and distance laboratories extend the application area of the web. This leads to an openly integrated environment which facilitates the sharing of not only educational material, but also hardware and software resources.
\end{abstract}

\section{Introduction}

Distance learning has been promoted across the entire education sector due to the increasing number of people that educate themselves after their working hours, or as part of their professional development. Furthermore, universities and high schools already use the Internet extensively for communication with their students. This, combined with the recent developments with regards to the Internet and information technology, has seen the need for web-based teaching grow rapidly.

Distance-learning, via the Internet, focuses on the delivery of information to the student, typically via web pages which are rich with multi-media content. The student, sitting at home in front of the computer, receives lessons in a certain subject while keeping contact with the other students as well as with the teacher via e-mail, chat-rooms, on-line tests, etc. Other issues focus on the style of teaching by using multi-media like video-clips, audio or "slide shows" extensively within the classroom, or alternatively from a distance (internet). Advanced educational material makes use of interactive 
programs, in the form of little experiments performed via a simulator or alternatively solving some engineering problems, in combination with the text explaining the theory.

However, it is crucial for students to gain this practical experience. Physical experiments give the students a feeling for practical testing. This also enables them to see the influence of second/higherorder, real-time and even parasitic effects which are often difficult or even impossible to simulate perfectly. The reason is that the simulations are always based on approximate or simplified models. Therefore it is important to give the students a real world experience. However, building an experiment is expensive and it is impossible for an educational institute to have the complete range of experiments. The hardware experiment should therefore be adapted in such a way that it can also be accessed from the Web. In this way the advances in ICT will be combined with the real world. The proposed virtual (distance) laboratory is not a web-based simulation. It is a real electro-technical experiment conducted in the laboratory, but it is remotely controlled and monitored by web-based tools. It is even possible to visualize the measuring instrument, the electronic components and many more factors such as lay-out, for example. This facility is useful to fulfill today's requirements for teaching over the Internet.

The experiments should not only be orientated to analysis (to measure and see the results) but also to synthesis. It should therefore include at least one design aspect. Therefore, the measurements are designed as a project based on a leading idea and with clear targets. First of all the technology of such an integration attempt, and thereafter guidelines to achieve distance Interactive Practical Education, are defined. This technology will be applied to the education of practical power electronics.

\section{Leonardo da Vinci project}

Leanardo da Vinci EU project is suggested and approved to create a full set of distance laboratories. Twelve universities with the span across the EU are participating in the project. The expected specific results are:

1. Learning objectives for the distance experimental education

2. Guidelines for project oriented measurements with the learning objectives for distance and /or virtual practical education,

3. Synthesis oriented experimental measurements,

4. Technology and technical documentation for distance practical education and measurements via the Internet,

5. Different designed measurements each with its own philosophy

The following modules are proposed (grouped into sets of modules) covering fundamentals and basic applications of the EE and advance topics including the application as well.

\section{Table I: The modules of the Leonardo project}

1. Fundamentals of Electrical Engineering

1.1 Single Phase and Three Phase Rectifier Circuits

1.2 DC Circuit Measurements and Resonant AC Circuits

2. Power Electronics

2.1 Power Converters

2.2 Power Factor Correction

2.3 PWM Modulation

2.4 DC-DC Converter for Renewable Energy Sources and Microgrid

2.5 Power Quality and Active Filters

2.6 Power Quality and/or Electromagnetic Compatibility
3. Electrical Machines

3.1 Basic Electrical Machinery - Synchronous Generator

3.2 DC Machines

3.3 Basic Electrical Machinery - DC Motor

3.4 Basic Electrical Machinery - Asynchronous Motor

4. Electro-Mechanical and Motion Control Systems

4.1 Basic Elements of Internet based Telemanipulation

4.2 Mechatronics, HIL (Hardware in the Loop) Simulation

4.3 High Dynamic Drives - Motion Control

4.4 A Automotive Electrical Drive

4.5 Complex Control of a Servodrive by a Small Logic Controller

4.6 Intelligent Gate Control by a Small Logic Controller (SLC) 
The outputs from the project will present teaching material (in electronic form; guidelines, manuals, documentation in English and other languages), further distance and virtual Laboratories approached via web, visualisation and the Lay out of the measured system and the measurement results obtained via Internet.

\section{Power Electronic Experiment}

In the DelftWebLab which is a part of PEMCWebLab system (www.PEMCWebLab.com), two measurements have been prepared (see Figure 2). These are the two basic conversion possibilities, namely dc-dc and dc-ac. Only the first application measurements, namely with the dc-dc converter is described here. The dc-dc buck converter was selected (step down chopper) with a resistive load which will later be extended to a dc machine. This converter topology is selected because it forms a basic building block for a voltage source inverter. This practical set-up of a buck converter is therefore extended to a switching leg of an inverter in the final part.

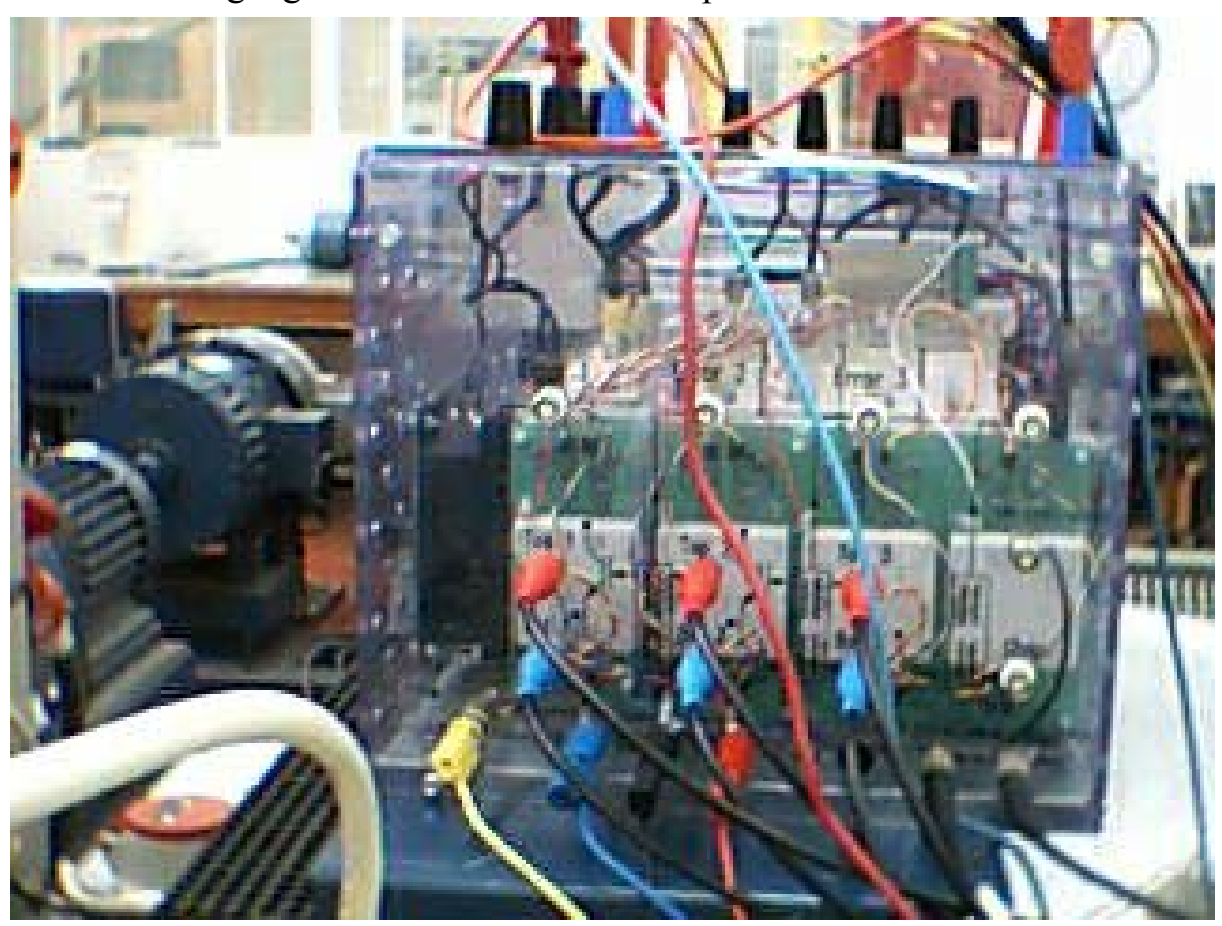

Figure 1 Lay-out of the DelftWebLab system

A dc-dc converter, and the demonstration of a three-phase inverter with vector modulation, was thus selected as the two systems to be measured in this way. General learning objective is to be able to follow some design steps of a power converter on a well structured way

\section{General objective}

The general objective is to be achieved by the following specific objectives:

Understand the structured design methodology

Learning the different energy conversion methods

Learning, that the lay-out of the real system has some rules. (hypotheses that the rules are known)

See the volume, lay-out and relate it to the power.

Be able to analyze an existing system in a structured way

Complex systems divide to subsystems for functional level

Learning, that the simulation (PC) and the real world effects are different and be able to understand the differences. Simulation (models) simplification of the reality

Be able to select an apparatus

To program the microcontroller with a specific goal

To understand the delays in the drivers

Requirements on the system are:

See and control the real system 
Must be accessible for all students

Design issue is to design a dc/dc converter with the given load and requested current ripple

\section{Objectives of the practical}

The objectives of the practical can be summarized by the following points:

Simulate a typical design process of a converter

Show the physical layout and construction of a modern converter

Demonstrate the switching effects of power semiconductor switches (e.g. switching on/off and reverse recovery)

Demonstrate the real time effects, delays in the drivers etc.

Compare the simulated and measured waveforms. Show the influence of the parasitic elements

\section{Design process}

The main idea behind this practical is to simulate a typical design process of a power converter. The design aspect has already been identified a very important part, and is in contrast with the traditional practical where the objective is to only observe the different phenomena.

The design process can be characterized with the following steps:

Simulation of the desired system

Programming of a microcontroller to generate pulses for the power converter

Assembling of the breadboard using the available building blocks

Measuring the real signals of the system and running the breadboard with a self-built (programmed)

modulator

Comparison of simulated and measured waveforms concerning delays and real time effects, etc.

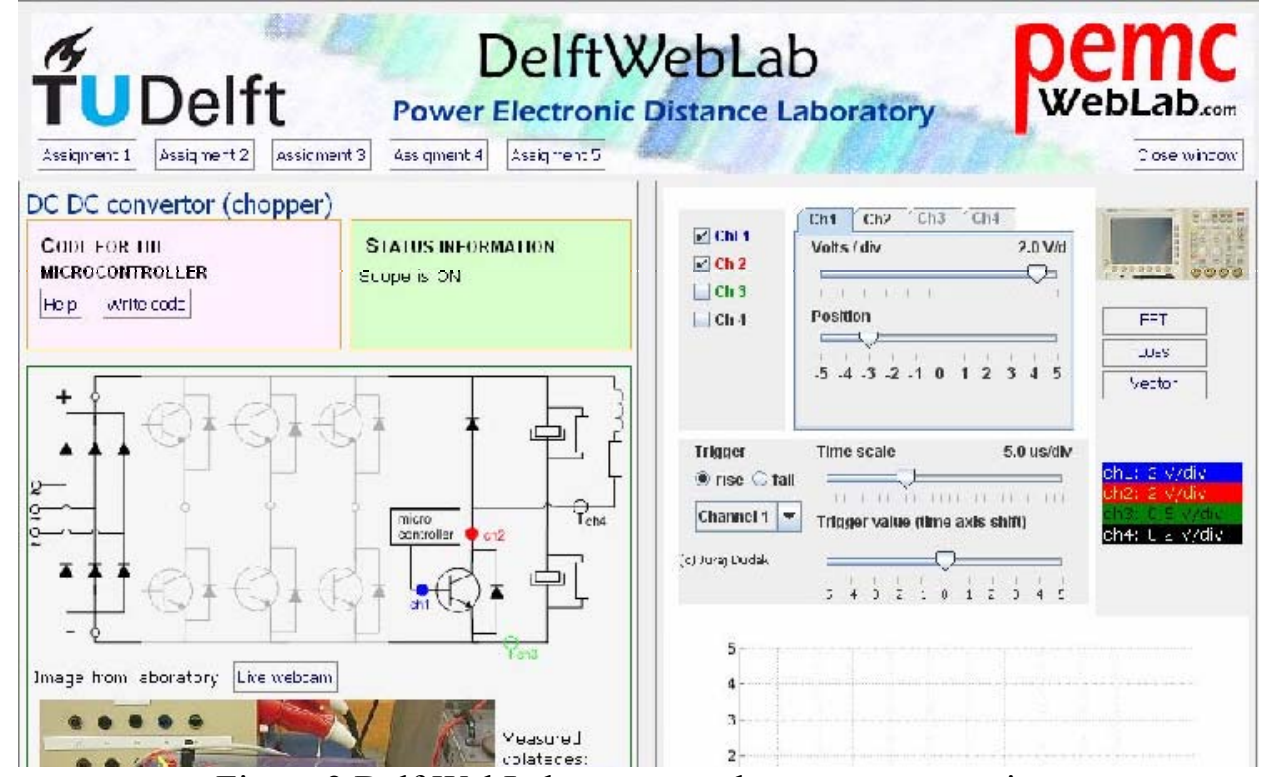

Figure 2 DelftWebLab system and measurement points

To guide the design process five different assignments are prepared.

\section{Assignment 1:Simulation and animation}

The aim of the simulation is to prepare the student for the practical, get acquainted with the basic problems and the working of the converter. The component values for the simulated system are the same as will be used later for the breadboard. There is an option to connect to remote simulation tools shown in Figure 3 to DelftWebLab. A vnc server web interface was used as the connecting application. After clicking on the remote simulation icon, a new page will be displayed prompting the user to enter a password. This password is needed in order to provide a secure connection. (To use this connection, the Java support must be installed on the users' computer.) After connecting to the remote computer, a simulation program can be run. Simulation of the converter system is performed with the 
simulation program labelled Caspoc [20]. The user-friendly interface allows one to simulate simple examples such as the buck converter. The use of a Scope feature is in this case similar to a real scope (Figure 3).

Performing simulations is an excellent preparation for the measurement itself. There is a possibility to change the power circuit and its configuration by dragging and dropping of the respective components. One of the interesting features of Caspoc is its animation capability: next to the oscilloscope waveforms it is possible to see whether the switch is on or off, or to follow the flow of the current. A change in the control strategy or any of the circuit parameters influences the power flow. This remains in spite of the fact that the simulated waveforms are somehow idealized. In fact, it can be considered as an advantage that the simulated waveforms are measured without parasitic and hindrance of measurement noise, for the comparison with the real-time effects will be made later during the actual measurement.

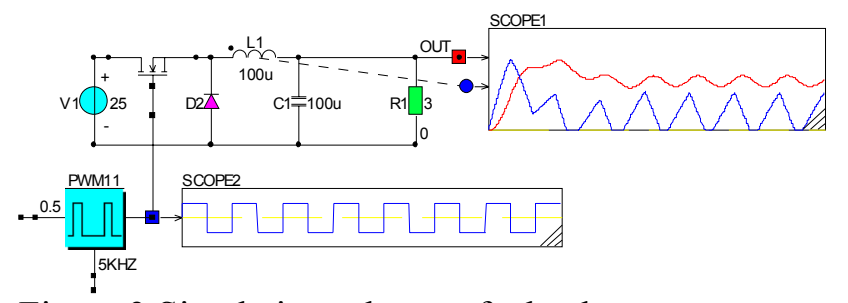

Figure 3 Simulation scheme of a buck converter

\section{Assignment 2: Programing the microcontroller}

To generate the pulses, the capture/compare unit (CCU) of the XC866 microcontroller is used. Every register is divided into 2 parts: the lower word and upper word because the CCU works in a 16-bit mode. The program shown below generates pulses at a frequency of $5 \mathrm{kHz}$. To be able to use the code for other micro controllers we will use the high-level language $\mathrm{C}$ instead of assembler. Once we have the $\mathrm{C}$-code, this code can be converted to controller-specific assembler code with an appropriate conversion programme. The $\mathrm{C}$-program that is needed for this practical consists of a limited number of lines of source code. The complete development cycle from 'idea' to working system will be demonstrated with a completely integrated development environment that will show all the steps that have to be done to obtain a working pulse width modulator. Exactly the same procedure has to be followed to realize much more complicated real-time applications.

To minimize the programming and assembly effort a so-called SoC (System on a Chip) is used, that enable effective use of libraries of subsystems that are supplied by the manufacturer of the system. Within certain system architecture, most manufacturers have developed a range of specific modules and subsystems for different application fields. Typical modules are CPU's, memories, interfaces but also modulators. For high volume markets these modules may be integrated on a single chip resulting in a SoC, One of the application fields is power electronics, as it requires high speed real-time signal processing and control. Modules for power electronic have in common that they should be able to generate PWM signals (pulse width modulated).

The micro controller that is used for this practical is the C504 manufactured by Infineon (was Siemens). The C504 is an 8-bit micro controller universally applicable for speed control of (small) AC induction motors.

\section{Assignment 3: Measurement of the delays}

After the microcontroller has been successfully programmed the measurement of the buck converter can commence. On the circuit diagram several measurement points (colored circles) have been prepared. The filled circles represent voltage values, and the clear circles represent current values. The measured points of the dc-dc buck converter are shown in Figure 2. They are the voltage over the switching device, over the gate driver and the current through the load. Comparing the simulation and the real time aspects measured on the system is an important aspect. The delays in the control electronics, switching operation and other important issues can be studied in detail at this stage. The third assignment is thus to consider the switching behaviour such as the delay and the transition times of the switch. The questions to answer are: What is the delay in the drivers and in the switch? What is 
the rise and fall time of the used IGBT switch? In Figure 4 measurement result of the delays measurement is shown.

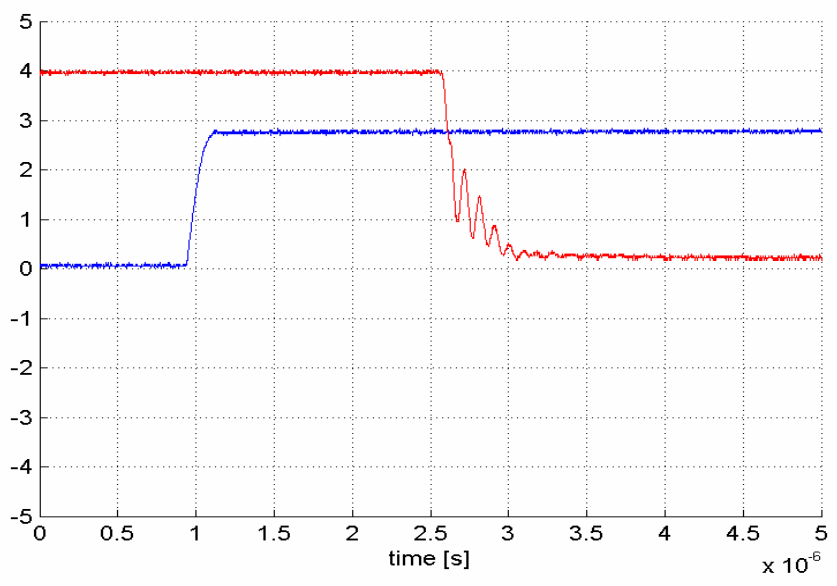

Figure 4 Measurement of the delay in the drivers and switch

\section{Assignment 4: Switching losses and diode reverse recovery}

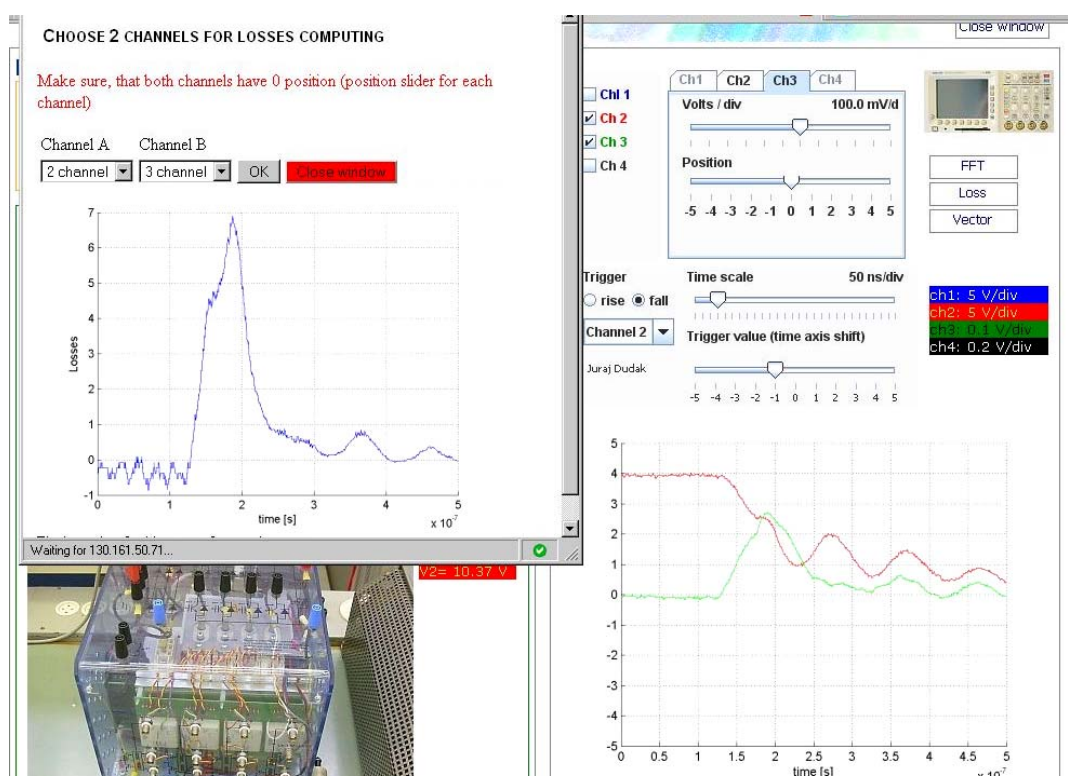

Figure 5 Measurement of the switching losses

Loss measurement is enabled and pre-programmed within the DelftWEbLab. Two scope channels are multiplied within the Matlab and hereby e.g. losses of the semiconductor switch (voltage x current) measured, The assignment is to measure the switching losses and conducting losses during one switching cycle. The assignment and questions to answer are: Which losses are higher the turn on or the turn off losses? The student can use hereby for the multiplication the button losses. Task 2 is to measure the reverse recovery of the diode.

\section{Assignment 5: DC machine}

In last assignment the student has to replace the RL load by a DC machine, where the machine parameters are known from the simulation. The assignment is to control the voltage at the armature of the DC machine such that the DC machine will rotate at a predetermined speed. For these machines a speed of $1200 \mathrm{rpm}$ corresponds to an armature voltage of $100 \mathrm{~V}$. 
Calculate the required values of $\mathrm{D}$ for 300,600 and $1000 \mathrm{rpm}$.

Set $\mathrm{D}$ at the appropriate value and check the speed.

Compare the voltages $\left(V_{1} \& V_{2}\right)$ and the current $I_{2}$ with the results of the simulation.

Consider the switching behaviour such as the delay and the transition times of the switch.

\author{
Assessment \\ Important part is assessment. The learning objectives are verified by: \\ Delays and maximum switching frequency \\ Switching losses \\ Achieved current ripple
}

\title{
Reactive Power Compensation
}

\section{Educational objectives}

Make the students familiar with:

power quality terms, definition of space vectors, control within orthogonal and rotating coordinates, advantages and disadvantages / side effects of active compensation.

Visualisation of load, grid and compensator voltages and currents, with and without an active filter.

\section{Assignments to the students}

The test set-up does not allow modifications to the control algorithm, therefore details concerning the control principle are learned using simulations, which then are verified by the experiment. This also reduces the time for which the experiment is needed, so allowing more students access to the experiment.

The first step is to learn about reactive power (fundamental frequency non-active power) compensation "Statcom operation". The simulation features a supply "grid", including sinusoidal generator voltages described by the space vector ug and a grid impedance given by resistance and inductance correctly describing the laboratory conditions (Figure 6).

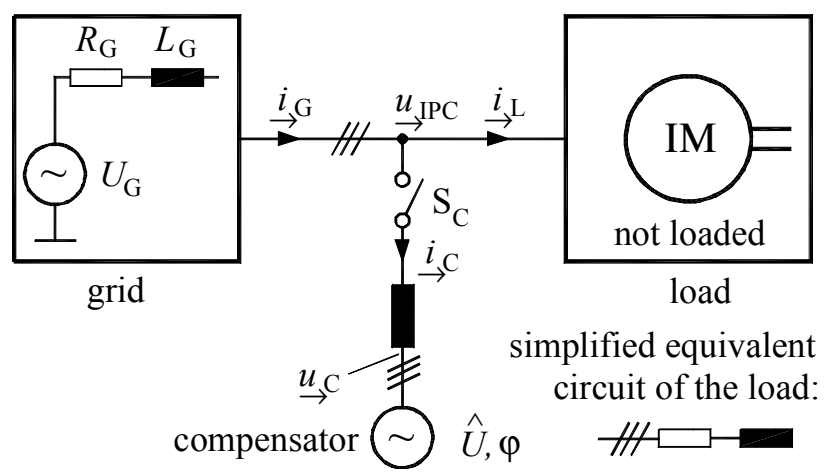

Figure 6 Principle schematic of STATCOM

An induction machine in idle state is connected to this supply, causing mainly reactive currents. A voltage source compensator, represented by sinusoidal fundamental frequency voltages, can be connected to this set-up by a switch Sc. Amplitude and phase of the compensator voltages have to be calculated and set by the student in order to compensate the reactive current. The calculation is based on compensating currents rather than powers, because in energy distribution voltages can be regarded as given and current components carry the information needed to decide what could or should be compensated. 
The basics of the calculations needed are, of course, given in the manual. To show the effect of the compensation, meters show active power, reactive power, apparent power, cosine phi and power factor. For the compensator, active and reactive power are shown on meters, too.

In a first step the student set the values derived for compensation and observes the compensator voltage in comparison to the grid voltage. Then the student closes the switch Sc. If the values set are correct, cosine phi and power factor are equal to one, reactive power vanishes and active and apparent power become identical. As the active power of the compensator remains zero, no energy source is required for this kind of compensation in the ideal case.

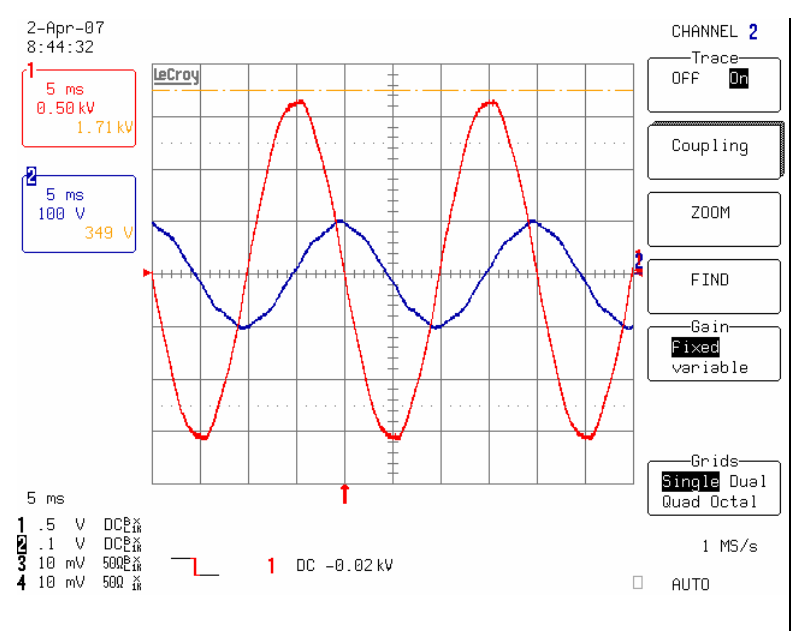

Figure 7 Voltage and current of uncompensated waveform

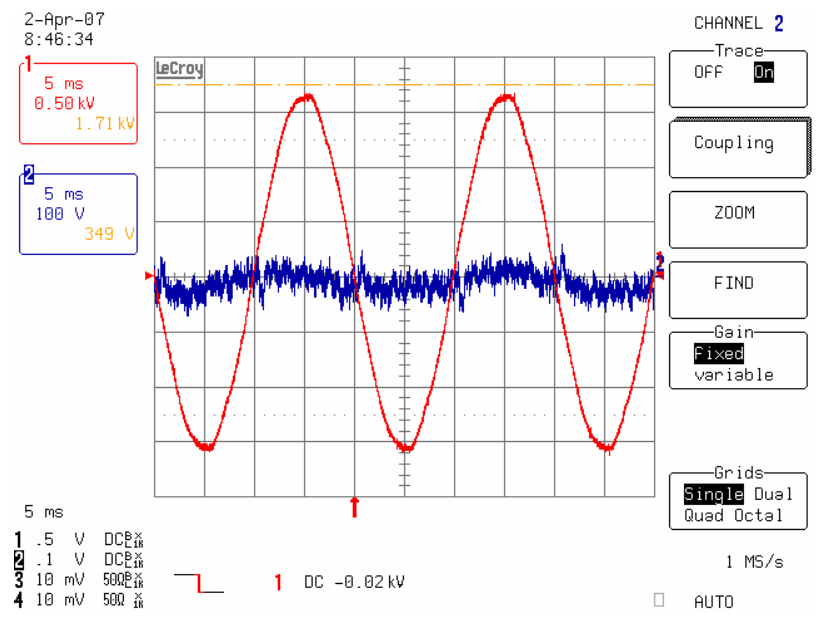

Figure 8 Voltage and current after compensation

From this the student learns that reactive power can easily be compensated, reducing grid currents and apparent power, such saving energy, increasing the amount of energy which can be delivered and reducing generator loading.

\section{Active filter}

In this assignment harmonics are to be compensated. The set-up for the simulation (Figure 8) is similar, but now the load consists of a six-pulse diode bridge with capacitive smoothing. To its capacitor a resistor load can be connected by switch SL. The compensator now contains several voltage sources in series, which each deliver sinusoidal voltage with selectable amplitude, phase angle and frequency.

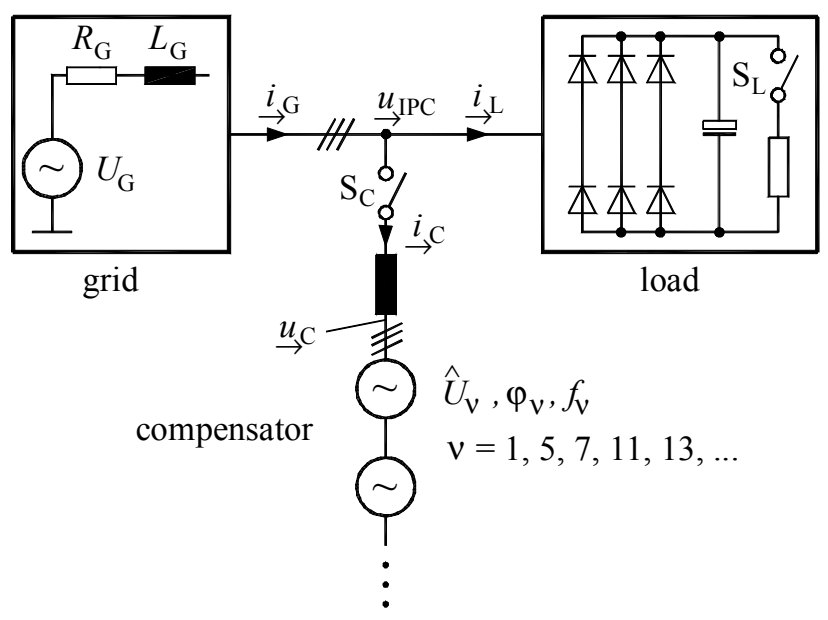

Figure 9 Principle schematic of laboratory with active filter 
The students first monitor voltages and currents. They notice that after closing switch SL - due to the grid impedance and the non-sinusoidal load currents - the measurable grid voltage becomes nonsinusoidal. Time functions and FFT results are presented, characteristic harmonics (3rd, 5th, 11th, 13th) can be found in current and voltage. Randomly each student has to compensate a given current harmonic by calculating the associated compensator voltage (amplitude, phase, frequency) based on the load current FFT results. The methodology is very similar to the one learned in assignment A.

Again, first the voltages are monitored with switch Sc open. Closing Sc removes the selected current harmonic from the grid current - but not from the load current. This can be seen clearly by comparing the respective FFT results.

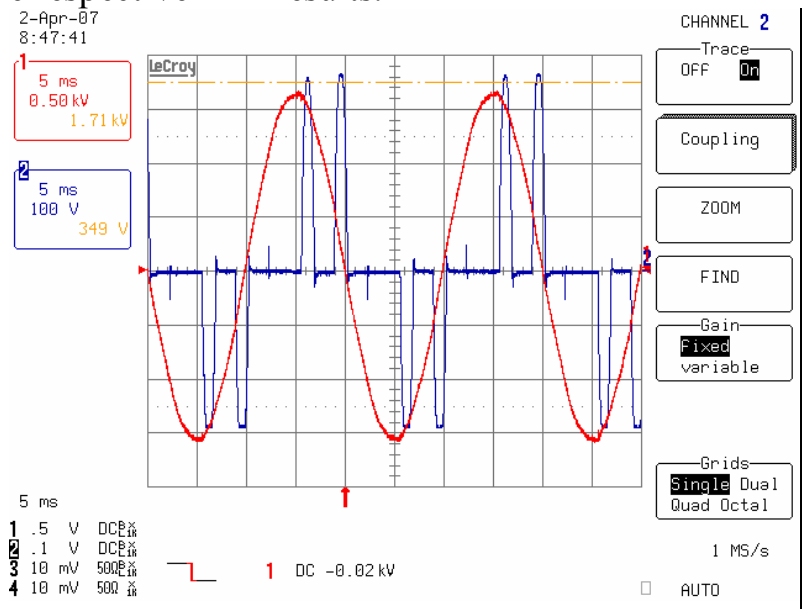

Figure 10 Voltage and current of a nonlinear load

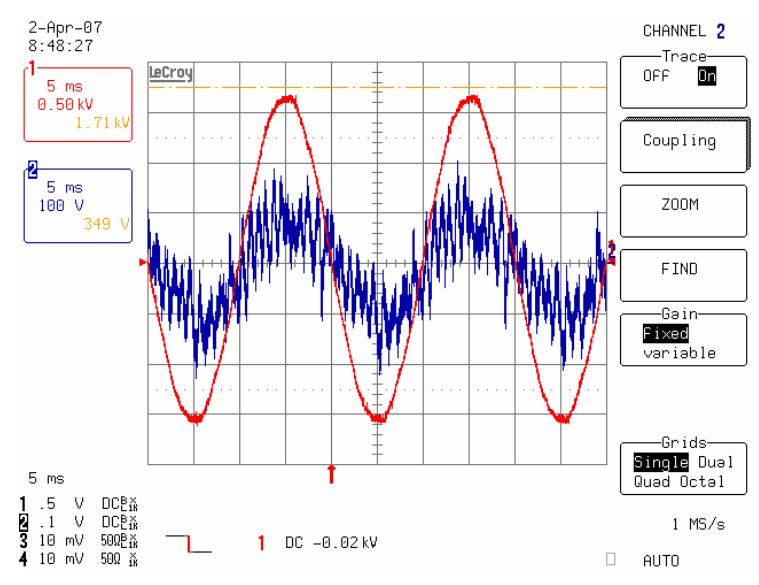

Figure 11 Voltage and current after active filtering

With the same principle, one more harmonic has to be compensated. This shows that the compensation of the current harmonics is independent of each other. In following assignment the simulation structure contains the complete control for controlled elimination of a certain harmonic. Proportional and integral part of a PI-controller can be selected, leading to variations in dynamic performance. The output of the controller and the reaction of the compensator can be monitored.

With these three assignments completed, the students can perform the experiment itself, they close this part of the lab by comparing and discussing the output of the simulation with the measurements resulting from the experiment.

One of the main differences between the experiment and the simulation is the upcoming of unavoidable high-frequency harmonics caused by the PWM of the active filter. When discussing measurements, the students should also discuss these high-frequency harmonics and their side-effects on other equipment, e.g. increased heating-up of a transformer.

\section{References}

[1] P. Bauer, et al. "Distance Practical Education in Power Electronics". International Journal of Engineering Education. 2007, 9. pages. ISSN 0949-149X/91, in press.

[2] P. Bauer, J. Dudak, and D. Maga, "Distance Practical Education with DelftWebLab". In EPE-PEMC 2006. Maribor: [University of Maribor], 2006. pp. 2111-2117. ISBN 1-4244-0121-6.

[3] D. Maga, et al. "E-learn Laboratory of Electromechanical Actuators". In Mechatronika 2005. Trenčín: TnUAD Trenčín, 2005. pp. 46-51. ISBN 80-8075-058-0.

[4] D. Maga, Elektromechanics 2 - guides to laboratory excercises (in Slovak). Trenčín: TnUAD Trenčín, 2002. 75 pages. ISBN 80-88914-59-0.

[5] S. Uran, D. Hercog, and K. Jezernik, "Remote Lab Experiment RC Oscillator for Learning of Control", International Journal of Online Engineering, vol. 2, no. 4, 2006.

[6] G.W.Chang ,Z.M Yeh, H.M,Chang, S.Y.Pan, "Teaching Photonics Laboratory Using Remote Control Web Technologies" IEEE Trans. On Education, Vol. A247, pp. 529-551, April 1955.

[7] B.Szabados: Interactive Outcome based Assesment using Multimedia, Int. J. Engng Ed. Vol. 20, No.2, pp. 141-151, 2004

[8] P.Penfield, R.C.Larson,"Education via Advanced Technologies, IEEE Trans. On Education, Vol. 39, No 3, pp. 436-442, April 1996. 
[9] C.Fernandez, O.Garcia.J.A.Cobos, J.Uceda,"Self-learning Laboratory Set up for Teaching Power Electronics Combining Simulations and Measurements

[10] K.W.E Cheng, C.L.Chan, N.C.Cheung, D.Sutanto,"Virtual Laboratory Development for Teaching Power Electronics, EPE-PEMC 2004 Riga, Latvia

[11]Z.Yi, J.Jian-jun, F.S.Chun: A LabVIEW -based ,Interactive Virtual Laboratory for Electronic Engineering Education; Int. J. Engng Ed. Vol. 21, No. 1, pp. 94-103, 2005

[12] A. B. Buckman: VI-Based Introductory Electrical Engineering Laboratory Course; Int. J. Engng Ed. Vol. 16 , No. 3, pp. $212 \pm 217,2000$

[13] C. S. Peek, O. D. Crisalle,S. Deapraz, D. GILLET: The Virtual Control Laboratory Paradigm: Architectural Design Requirements and Realization Through a DC-Motor Example; Int. J. Engng Ed. Vol. 21, No. 6, pp.
$1134 \pm 1147,2005$

[14]C. Fernandez, M A. Vicente, L.M. Jimenez: Virtual Laboratories for Control Education: a Combined Methodology; Int. J. Engng Ed. Vol. 21, No. 6, pp. 1059 $\pm 1067,2005$

[15]N. Ertugrul: New Era in Engineering Experiments: an Integrated and Interactive Teaching/Learning Approach, and Real-Time Visualisations; Int. J. Engng Ed. Vol. 14, No. 5, pp. 344 $\pm 355,1998$

[16] V. G. Agelidis: A Laboratory-Supported Power Electronics and Related Technologies Undergraduate

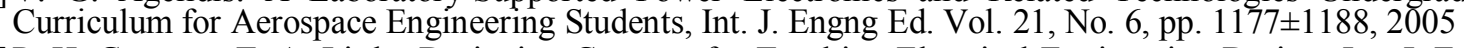

[17]P. H. Gregson, T. A. Little: Designing Contests for Teaching Electrical Engineering Design; Int. J. Engng Ed. Vol. 14, No. 5, pp. $367 \pm 374$, 1998

[18] N. Ertugrul: Towards Virtual Laboratories: a Survey of LabVIEW-based Teaching/ Learning Tools and Future Trends; Int. J. Engng Ed. Vol. 16, No. 3, pp. 171 $\pm 180,2000$

[19] Matlab, www.mathwors.com

[20] Caspoc, www.caspoc.com

[21]B. Lu, X. Wu, H. Figueroa, and A. Monti, "Implementation of a lowcost real-time virtue test bed for hardware-in-the-loop testing," in Proc. The 31st Annual Conference of the IEEE Industrial Electronics Society (IECON'2005), North Carolina, USA, Nov. 2005, pp. 239-244. 